\title{
Produção de hidrolisado proteico de pirarucu utilizando-se protease de Aspergillus flavo-furcatis e pancreatina ${ }^{1}$
}

\author{
Flávia de Carvalho Paiva ${ }^{2}$, Mircella Marialva Alecrim³, \\ Maria Francisca Simas Teixeira ${ }^{3}$, Larissa de Souza Kirsch ${ }^{3}$, Rogério Souza de Jesus ${ }^{4}$
}

\begin{abstract}
Production of arapaima protein hydrolysate using Aspergillus flavo-furcatis protease and pancreatin

The processing of arapaima (Arapaima gigas) generates a lot of residues that can be used for the development of new products of industrial interest. This study aimed at evaluating the production of protein hydrolysates from arapaima residues using Aspergillus flavo-furcatis protease and commercial pancreatin, as well as characterizing their nutritional and microbiological qualities. The raw material used was meat mechanically separated from arapaima carcasses (MMSA). Two products were developed: a protein hydrolysate of arapaima using a commercial enzyme (PHACE) and another one using microbial enzyme (PHAME). The MMSA and the hydrolysates were analyzed for chemical composition, microbiological quality, degree of hydrolysis, digestibility and amino acid profile. The results showed that the PHACE protein content was $73.47 \%$. This value was significantly higher, when compared to the PHAME $(58.03 \%)$. However, both products showed high digestibility values, absence of microbial contaminants and reduced lipid content. Among the enzymes used, pancreatin was the most efficient one in the preparation of the final product, which showed essential amino acids content higher than the requirements for human adults. The hydrolysate developed using A. flavo-furcatis enzymes presented essential amino acids score lower than 1.0, being tryptophan the most limiting one.
\end{abstract}

KEY-WORDS: Aspergillus sp.; residue utilization; fish byproducts.

\section{INTRODUÇÃO}

O pirarucu (Arapaima gigas), conhecido popularmente como Gigante da Amazônia, tem vasta distribuição na Bacia Amazônica, sendo o maior peixe dulcícola de escama do mundo. Na Região

\section{RESUMO}

O beneficiamento do pirarucu (Arapaima gigas) gera grande quantidade de resíduos que podem ser aproveitados para a elaboração de novos produtos de interesse industrial. Este estudo objetivou avaliar a produção de hidrolisados proteicos a partir de resíduos de pirarucu, utilizando-se proteases de Aspergillus flavo-furcatis e pancreatina comercial, além de caracterizálos quanto às suas qualidades nutricional e microbiológica. A matéria-prima utilizada foi carne mecanicamente separada de carcaças de pirarucu (CMSP). Dois produtos foram desenvolvidos: um hidrolisado proteico de pirarucu produzido com enzima comercial (HPPEC) e outro com enzima microbiana (HPPEM). A CMSP e os hidrolisados foram submetidos à análise de composição química, qualidade microbiológica, grau de hidrólise, digestibilidade e perfil de aminoácidos. Os resultados mostraram que, no HPPEC, o teor proteico foi de 73,47\%, significativamente superior ao do HPPEM (58,03 \%). Todavia, os dois produtos apresentaram altos valores de digestibilidade, ausência de contaminantes microbianos e redução no conteúdo de lipídios. Entre as enzimas utilizadas, a pancreatina foi a mais eficiente na elaboração do produto final, que demonstrou conteúdo de aminoácidos essenciais superior aos requerimentos para humanos adultos. O hidrolisado desenvolvido com as enzimas de $A$. flavo-furcatis apresentou escore de aminoácidos essenciais inferior a 1,0 , sendo o aminoácido mais limitante o triptofano.

PALAVRAS-CHAVE: Aspergillus sp.; aproveitamento de resíduos; coprodutos de pescado.

Amazônica, seu consumo é um hábito tradicional, que tem se expandido para outras regiões, devido ao sabor de sua carne, valor nutritivo e também comercial (Mueller \& Green 2006, FAO 2010).

Desde 1975, o pirarucu encontra-se na lista dos animais silvestres ameaçados de extinção. Portanto,

1. Trabalho recebido em maio/2014 e aceito para publicação em mar./2015 (http://dx.doi.org/10.1590/1983-40632015v4529838).

2. Universidade Federal do Amazonas (UFAM), Faculdade de Ciências Farmacêuticas, Manaus, AM, Brasil.

E-mail: paiva.flac@gmail.com.

3. Universidade Federal do Amazonas (UFAM), Instituto de Ciências Biológicas, Departamento de Parasitologia, Manaus, AM, Brasil.E-mails: mircella.ma@gmail.com,mteixeira@ufam.edu.br,1_kirsch@hotmail.com.

4. Instituto Nacional de Pesquisas da Amazônia (INPA), Coordenação de Pesquisa em Tecnologia de Alimentos, Manaus, AM, Brasil.E-mail: djesus@inpa.gov.br. 
no Estado do Amazonas, a sua exploração deve ser devidamente regulamentada. Para garantir a conservação dessa espécie, nos últimos anos, a pesca passou a ser regulada, em áreas protegidas de uso sustentável, como, por exemplo, a Reserva de Desenvolvimento Sustentável de Mamirauá (RDSM), Amazonas, Brasil. Essa condição tem contribuído para o aumento da densidade de pirarucu e do número de pescadores nessas áreas (Arantes et al. 2006, Castello et al. 2009).

O pirarucu também tem atraído a atenção dos criadores de peixe da região Amazônica, pois apresenta grande potencial para a piscicultura, devido às suas características zootécnicas positivas para a criação intensiva, como rápido crescimento; capacidade de realizar respiração aérea, sem depender do oxigênio dissolvido na água; fácil adaptação ao consumo de rações comerciais; carne de alta qualidade; e alto rendimento de carcaça (Freitas-Júnior et al. 2012).

Por ser um peixe de grande porte e, devido à sua crescente comercialização, o beneficiamento do pirarucu gera uma quantidade considerável de resíduos, incluindo cabeça, vísceras, nadadeiras, escamas, carcaça e couro, os quais podem ser considerados subprodutos e agregar valor à produção (Freitas-Júnior et al. 2012).

Uma forma de se aproveitar o resíduo gerado no processamento industrial do pirarucu e minimizar a poluição ambiental é por meio da hidrólise enzimática, alternativa que proporciona o aproveitamento da proteína e resulta na produção de hidrolisado proteico de pescado (HPP), que pode apresentar elevada digestibilidade, bem como propriedades físico-químicas, funcionais e nutricionais interessantes (Nguyen et al. 2011, Oliveira et al. 2014).

Os hidrolisados proteicos são utilizados como fonte de pequenos peptídios e aminoácidos, podendo enriquecer a alimentação humana e animal, além de ser fonte de nutrientes no cultivo de micro-organismos (Nguyen et al. 2011, Oliveira et al. 2014).

Para a fabricação de hidrolisados proteicos, o substrato, comumente, pode ser submetido à hidrólise alcalina, hidrólise enzimática e hidrólise ácida, ou à combinação de dois ou mais desses métodos (Oliveira et al. 2014). Dessas técnicas, a hidrólise enzimática torna-se vantajosa, em função da especificidade da enzima com o substrato, controle do grau de hidrólise e condições moderadas de ação, e proporciona a liberação de peptídeos biologicamente ativos (Zavareze et al. 2009, Oliveira et al. 2014).
Entre as proteases utilizadas na hidrólise proteica, estão disponíveis no mercado a papaína, pepsina, tripsina, quimotripsina, pancreatina, alcalase, flavourzyme, pronase e bromelina (Galla et al. 2012).

Diversas pesquisas são constantemente realizadas, objetivando a descoberta de novas fontes proteolíticas de maior eficiência. Nesse sentido, as enzimas de origem fúngica têm sido muito utilizadas na indústria, devido às suas propriedades bioquímicas, facilidade de cultivo e possibilidade de manipulação genética das linhagens. Dentre esses micro-organismos, várias espécies do gênero Aspergillus são consideradas seguras e potenciais produtoras de proteases, com atividade em ampla faixa de $\mathrm{pH}$ e temperatura (Agrawal et al. 2004, Sandhya et al. 2005, Upadhyay et al. 2010, Rodarte et al. 2011). Um exemplo desse gênero é o Aspergillus flavo-furcatis Batista \& Maia, espécie anamórfica que é citada como produtora de protease (Teixeira et al. 2012).

Este estudo objetivou desenvolver hidrolisados proteicos a partir de resíduos de pirarucu, utilizando-se o extrato enzimático bruto de A. flavo-furcatis e pancreatina comercial, bem como caracterizá-los quanto ao grau de hidrólise, composição química e qualidade microbiológica.

\section{MATERIAL E MÉTODOS}

As amostras de carcaças de pirarucu (A. gigas) provenientes da Reserva de Desenvolvimento Sustentável Mamirauá, em Maraã, Amazonas, Brasil, foram adquiridas em agosto de 2013. Para as análises, todas as amostras foram transportadas em caixas de isopor, entre camadas de gelo, até o Laboratório de Tecnologia de Pescado da Coordenação de Tecnologia e Inovação do Instituto Nacional de Pesquisa da Amazônia (INPA), em Manaus (AM). No laboratório, as amostras foram lavadas, cortadas em partes menores e processadas em máquina separadora de espinhas (BAADER 694, Lübeck, Alemanha), para obtenção de carne mecanicamente separada de pirarucu (CMSP). As amostras foram armazenadas a $-18^{\circ} \mathrm{C}$, até o momento do uso.

A hidrólise enzimática foi realizada com pancreatina (LabMaster Ltda, Pinhais, Brasil) e com proteases produzidas por uma linhagem de Aspergillus flavo-furcatis (DPUA 1493) da Micoteca do Departamento de Parasitologia da Universidade Federal do Amazonas (DPUA). Para a determinação da atividade enzimática, foi preparada solução aquosa 
$1 \%(\mathrm{p} / \mathrm{v})$ do extrato proteolítico bruto de A. flavo-furcatis liofilizado.

A atividade proteolítica foi determinada em triplicata, a $25^{\circ} \mathrm{C}$, utilizando-se, como substrato, azocaseína (Sigma, St. Luis, MO USA) a 1,0 \% (p/v), em tampão Tris-HCl 0,2M, pH 7,2. Uma unidade de atividade proteolítica foi definida como a quantidade de enzima capaz de produzir aumento na absorbância de 0,1 , em 1 hora (Kirsch et al. 2012). O efeito do $\mathrm{pH}$ foi avaliado na faixa de 3,0-10,0, em tampão citrato-fosfato $0,1 \mathrm{M}$, a $25^{\circ} \mathrm{C}$, e o efeito da temperatura na faixa de $25-70^{\circ} \mathrm{C}$, no $\mathrm{pH}$ ótimo de atividade (Fonseca et al. 2014).

O hidrolisado proteico de pirarucu foi preparado de acordo com o método descrito por Foh et al. (2011), utilizando-se a CMSP, como substrato, e a enzima pancreatina comercial e as proteases de A. flavo-furcatis, separadamente.

Este trabalho gerou depósito de registro de patente de produto e processo no Instituto Nacional da Propriedade Industrial (INPI), sob o número de registro BR 102014024507 3. Dessa forma, parte da metodologia sobre as condições ótimas de produção do hidrolisado proteico de pirarucu é de caráter sigiloso (proporção enzima/substrato, linhagem do micro-organismo utilizado para produção de enzima proteolítica, preparo da matéria-prima e etapas de recuperação do produto final).

$\mathrm{O}$ índice de solubilidade do nitrogênio foi utilizado para determinar o grau de hidrólise $(\mathrm{GH})$, utilizando-se ácido tricloroacético (TCA) como agente de precipitação (Hoyle \& Merritt 1995). O método de Micro Kjeldahl foi usado para determinar o teor de nitrogênio e calculado de acordo com a seguinte equação:

$\% \mathrm{GH}=\frac{\text { (proteínas solúveis após a hidrólise - proteínas solúveis antes da hidrólise) }}{\text { proteína bruta do substrato }} \times 100$

A CMSP e os hidrolisados proteicos foram caracterizados, quanto à composição, em proteínas, lipídios, cinzas e umidade (AOAC 2000). A CMSP e os hidrolisados foram submetidos à avaliação microbiológica, por meio da pesquisa de Staphylococcus coagulase positiva, Salmonella sp., coliformes a $45^{\circ} \mathrm{C}$, bactérias aeróbias mesófilas, bolores e leveduras, conforme a Instrução Normativa 62/2003 (Brasil 2003). As análises foram realizadas em triplicata.

A determinação dos teores de aminoácidos foi efetuada por cromatografia líquida de alta performance (HPLC). As amostras passaram por hidrolisação prévia com ácido clorídrico $(\mathrm{HCl}) 6 \mathrm{~N}$, seguida de derivação dos aminoácidos com fenilisotiocianato (PITC) e separação dos derivativos feniltiocarbamilaminoácidos em coluna de fase reversa, com detecção por UV, a $254 \mathrm{~nm}$. A quantificação foi feita por calibração interna multinível, com o auxílio do ácido $\alpha$-aminobutírico (AAAB), como padrão interno para aminoácidos totais (White et al. 1986). A determinação de triptofano foi realizada após hidrólise enzimática com pronase e reação colorimétrica com p-dimetil amino benzaldeído (DAB), segundo Spies (1967). A partir dos dados dessas análises, foi estimado o escore de aminoácidos essenciais (EAE), sendo os valores do conteúdo de aminoácidos essenciais expressos em mg de aminoácido por $100 \mathrm{~g}$ de proteína e comparados com o padrão (WHO 2007).

A digestibilidade proteica in vitro foi determinada de acordo com o método de Akeson \& Stahman (1964), modificado. Uma quantidade conhecida da amostra foi incubada com $1,5 \mathrm{mg}$ de pepsina, em $15 \mathrm{~mL}$ de ácido clorídrico $0,1 \mathrm{~N}$, a $37^{\circ} \mathrm{C}$, durante 3 horas. Depois, a amostra foi neutralizada com solução de hidróxido de sódio $2 \mathrm{M}$ e foram adicionados $4 \mathrm{mg}$ de pancreatina a $10 \mathrm{~mL}$ de tampão fosfato $(\mathrm{pH} 8,0)$. Foram adicionados $2 \mathrm{~mL}$ de Merthiolate (Brainfarma Indústria Química e Farmacêutica S/A), para prevenir o crescimento microbiano, e a solução foi incubada por 24 horas, a $37^{\circ} \mathrm{C}$. Após 24 horas, a enzima foi inativada pela adição de $10 \mathrm{~mL}$ de ácido tricloroacético a $10 \%$, para precipitar a proteína não digerida. A amostra foi centrifugada a $8.000 \mathrm{xg}$, por 15 minutos. A proteína contida no sobrenadante foi determinada pelo método de micro-Kjeldahl (AOAC 2000) e a digestibilidade proteica in vitro expressa como a porcentagem do nitrogênio digerido, em relação ao nitrogênio total da amostra inicial, de acordo com a seguinte equação:

$$
\text { Digestibilidade }(\%)=\frac{\text { nitrogênio digerido }}{\text { nitrogênio total da amostra }} \times 100
$$

Para a análise estatística, foi utilizado o programa estatístico Minitab, versão 16.0. Os resultados foram analisados por meio de análise de variância (Anova) e teste Tukey $(\mathrm{p}<0,05)$, para comparação entre as médias.

\section{RESULTADOS E DISCUSSÃO}

Para o extrato bruto liofilizado de A. flavofurcatis (Figura 1), a atividade proteolítica deter- 


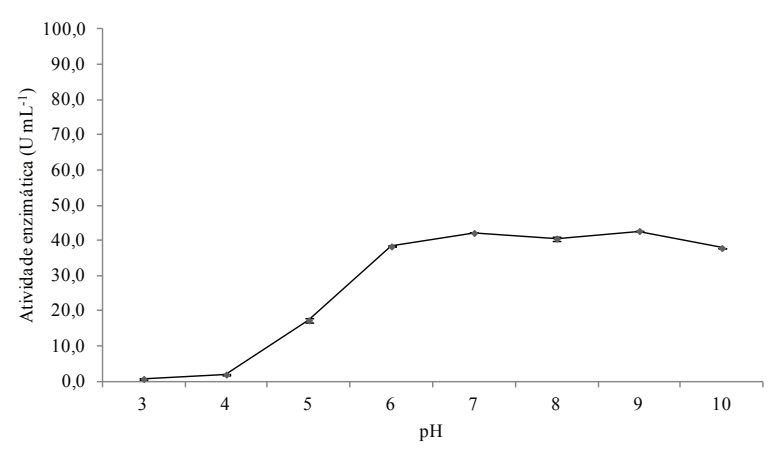

Figura 1. Efeito do $\mathrm{pH}$ sobre a atividade das proteases de Aspergillus flavo-furcatis (Manaus, AM, 2013).

minada foi de $31,20 \pm 0,13 \mathrm{U} \mathrm{mL}^{-1}$, utilizando-se azocaseína como substrato. Quando foi avaliado o efeito do $\mathrm{pH}$ na atividade, as proteases foram mais ativas na faixa de $\mathrm{pH} 6,0$ a 10,0, revelando maior presença de proteases neutras e alcalinas.

$\mathrm{Na}$ condição de análise, o $\mathrm{pH}$ de atividade ótima das proteases de $A$. flavo-furcatis foi determinado entre 7,0 e 9,0 , em que foram determinados os valores de atividade 42,16 $\pm 0,04 \mathrm{U} \mathrm{mL}^{-1} \mathrm{e}$ $42,69 \pm 0,10 \mathrm{U} \mathrm{mL}^{-1}$, respectivamente. Estudos com outras espécies de Aspergillus sp. relatam resultados similares aos observados neste estudo (Choulhary 2012, Kranthi et al. 2012). As proteases neutras reduzem o amargor das proteínas hidrolisadas nos alimentos, devido à ação de hidrólise em aminoácidos hidrofóbicos restritos ao $\mathrm{pH}$ neutro (Sandhya et al. 2005). Essa característica proporciona viabilidade de uso das proteases de $A$. flavo-furcatis, na produção de hidrolisados proteicos.

A temperatura de atividade ótima foi determinada na faixa de $25-80^{\circ} \mathrm{C}$, em pH 7,0 e 9,0 (Figura 2).

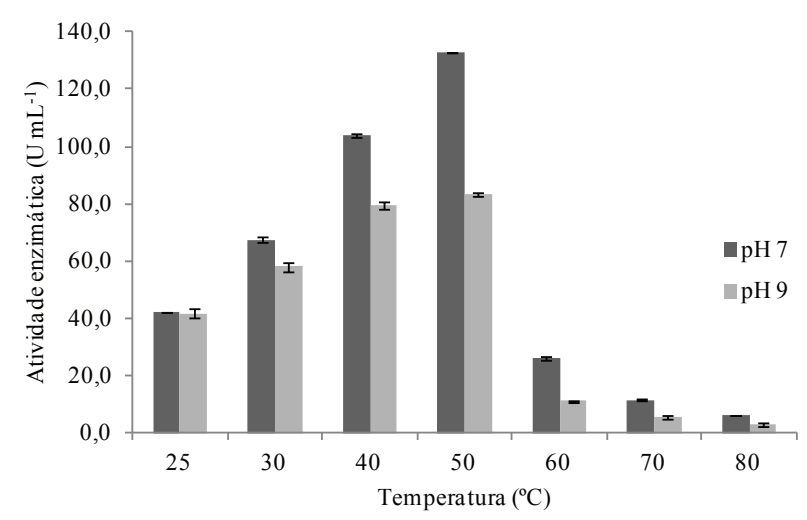

Figura 2. Efeito da temperatura sobre a atividade das proteases de Aspergillus flavo-furcatis (Manaus, AM, 2013).
A atividade das proteases foi observada em todas as temperaturas avaliadas, todavia, a máxima atividade ocorre em $50{ }^{\circ} \mathrm{C}\left(132,93 \pm 0,13 \mathrm{U} \mathrm{mL}^{-1}\right)$. Resultados semelhantes aos obtidos nesta pesquisa foram encontrados por Anitha \& Palanivelu (2013), para A. parasiticus.

O grau de hidrólise ( $\mathrm{GH} \%$ ) indica a quantidade de ligações peptídicas clivadas. Nos hidrolisados proteicos, foram observados diferentes $\mathrm{GH}$. O HPPEC apresentou maior GH $(40,49 \% \pm 047)$, significativamente superior ao obtido para o HPPEM $(20,67 \% \pm 0,87)$, nas mesmas condições.

$\mathrm{O} \mathrm{GH}$ é influenciado por diversos fatores, porém, neste estudo, a especificidade da enzima teve efeito pronunciado, como descrito por Neves et al. (2004). A especificidade do complexo proteolítico do fungo ainda é pouco conhecida. Já a pancreatina é uma combinação de endoproteases (tripsina, quimotripsina) e exoproteases (carboxipeptidases), proporcionando alto grau de hidrólise (Li et al. 2010). Portanto, a suscetibilidade da CMSP à hidrólise depende do tipo de enzima utilizada. Este resultado está de acordo com Klompong et al. (2007).

Ao término do processamento da CMSP, foram produzidos dois hidrolisados proteicos: um proveniente da hidrólise com as proteases de Aspergillus flavo-furcatis (HPPEM) e outro obtido com a pancreatina comercial (HPPEC). A composição química dos hidrolisados proteicos de pirarucu e da CMSP está apresentada na Tabela 1. O teor de umidade encontrado para a CMSP foi de $73,79 \%$, próximo aos valores relatados por Souza et al. (2013), que variaram de $71,8 \%$ a 79,7 \% de umidade, para CMS das espécies de peixes amazônicos aracu, jaraqui e mapará.

O teor proteico variou entre os hidrolisados, sendo que o HPPEC apresentou 73,47 \% de proteí-

Tabela 1. Composição química dos hidrolisados proteicos de pirarucu e da CMSP (base seca) (Manaus, AM, 2013).

\begin{tabular}{lcrr}
\hline $\begin{array}{l}\text { Parâmetro } \\
\left(\mathrm{g} 100 \mathrm{~g}^{-1}\right)\end{array}$ & CMSP $^{1}$ & \multicolumn{1}{c}{ HPPEM $^{2}$} & \multicolumn{1}{c}{ HPPEC $^{3}$} \\
\hline Proteína & $59,38^{\mathrm{B}} \pm 0,52$ & $58,03^{\mathrm{B}} \pm 1,61$ & $73,47^{\mathrm{A}} \pm 0,22$ \\
Lipídios & $34,21^{\mathrm{A}} \pm 0,12$ & $0,54^{\mathrm{B}} \pm 0,01$ & $0,34^{\mathrm{C}} \pm 0,03$ \\
Cinzas & $3,20^{\mathrm{C}} \pm 0,14$ & $33,55^{\mathrm{A}} \pm 0,95$ & $19,16^{\mathrm{B}} \pm 0,00$ \\
\hline
\end{tabular}

Cada valor representa a média da triplicata com desvio-padrão. Médias seguidas por diferentes letras, na mesma linha, indicam diferença significativa pelo teste Tukey $(\mathrm{p}<0,05) .{ }^{1} \mathrm{CMSP}=$ carne mecanicamente separada de pirarucu, com teor de umidade de $73,79 \mathrm{~g} 100 \mathrm{~g}^{-1} \pm 1,64 ;{ }^{2} \mathrm{HPPEM}=$ hidrolisado proteico de pirarucu obtido com enzima microbiana; ${ }^{3} \mathrm{HPPEC}=$ hidrolisado proteico de pirarucu obtido com enzima comercial. 
na, valor significativamente superior $(\mathrm{p}<0,05)$, em relação ao HPPEM $(58,03 \%)$. Os resultados deste estudo assemelham-se aos obtidos por Chalamaiah et al. (2012), que variaram de $37,7 \%$ a $97,57 \%$ de proteína. A hidrólise com pancreatina favoreceu o aumento do conteúdo de proteína da CMSP e a redução do teor de lipídios, enquanto a protease de A. flavo-furcatis promoveu redução do teor proteico e lipídico, em relação à CMSP (Tabela 1). No entanto, Neves et al. (2004), ao utilizarem diferentes concentrações de pepsina, bromelina e quimotripsina, obtiveram hidrolisados com teores proteicos inferiores ao da matéria-prima, devido à proteína não hidrolisada (proteína insolúvel).

Segundo Nilsang et al. (2005), a redução do teor de lipídios nos hidrolisados pode ser observada devido ao fato de a maior parte destes ser descartada junto com as proteínas não hidrolisadas, no processo de centrifugação para obtenção das proteínas solúveis. O baixo teor de lipídios encontrado nos hidrolisados é favorável, em relação à oxidação lipídica, ou seja, para maior estabilidade do produto, durante o armazenamento (Zavareze et al. 2009).

Neste estudo, o teor de cinzas sofreu elevação de 3,20\% (BS), na CMSP, para 33,55 \%, no HPPEM, e $19,16 \%$, no HPPEC. De acordo com Zavareze et al. (2009), o aumento no conteúdo de cinzas em hidrolisados proteicos é normal, em decorrência dos sais presentes nos tampões utilizados para manter o $\mathrm{pH}$, durante a hidrólise enzimática.

Na legislação brasileira vigente (Brasil 2001), não há padrões microbiológicos estabelecidos para carne mecanicamente separada (CMS) e para hidrolisados proteicos de pescado. Na CMSP, não foram encontrados Salmonella sp. e Staphylococcus aureus coagulase positiva, ou detectados bolores e leveduras. Foram encontradas bactérias mesófilas e coliformes termotolerantes, porém, os valores ficaram abaixo dos limites registrados na legislação para pescado in natura (Tabela 2 ).

Mesmo em pequeno número, a presença desses micro-organismos pode revelar a ocorrência de deficiências no processamento da CMSP. No entanto, após o preparo dos hidrolisados, houve redução total na biota microbiana, quando comparada à matéria-prima. Essa redução pode ser atribuída ao tratamento térmico empregado durante a obtenção dos hidrolisados, que, seguido de resfriamento, funciona como uma pasteurização, eliminando, de maneira eficaz, os micro-organismos existentes na CMSP (Veit et al. 2013), resultando em produtos seguros para o uso na alimentação humana e animal.

A composição e o escore de aminoácidos essenciais (EAE) da CMSP e dos hidrolisados proteicos (HPPEC e HPPEM) estão apresentados na Tabela 3. Entre esses dois produtos, os dados mostram que houve diferença no conteúdo de aminoácidos e no EAE. Os fatores que determinaram essas diferenças foram, provavelmente, as enzimas utilizadas na hidrólise, visto que a pancreatina comercial promoveu o aumento da concentração de aminoácidos livres, em comparação com a hidrólise realizada com o extrato enzimático bruto de A. flavo-furcatis (Pacheco et al. 2005).

Na composição de aminoácidos não essenciais, o HPPEC apresentou maior quantidade de aspartato, serina, arginina e prolina. Já no HPPEM, glutamato, glicina e alanina foram os predominantes. Os aminoácidos não essenciais aspartato e glutamato foram os que se destacaram na CMSP e nos hidrolisados. Esses resultados são similares aos citados por Chamalaiah et al. (2012).

No caso dos aminoácidos essenciais, os resultados mostram que o perfil de aminoácidos do HPPEC foi maior do que no HPPEM, com exceção

Tabela 2. Avaliação microbiológica da CMSP e dos hidrolisados proteicos de pirarucu (Manaus, AM, 2013).

\begin{tabular}{|c|c|c|c|c|c|}
\hline \multirow{2}{*}{ Micro-organismo } & \multicolumn{2}{|c|}{ Padrões permitidos } & \multicolumn{3}{|c|}{ Resultados encontrados } \\
\hline & Pescado in natura & Subproduto de pescado seco & $\mathrm{CMSP}^{1}$ & HPPEM $^{2}$ & $\mathrm{HPPEC}^{3}$ \\
\hline Salmonella sp. $^{4}$ & Ausente & Ausente & Ausente & Ausente & Ausente \\
\hline Coliformes termotolerantes ${ }^{4}\left(\mathrm{NMP} \mathrm{g}^{-1}\right)$ & $10^{2}$ & $10^{2}$ & $<10^{2}$ & Ausente & Ausente \\
\hline Staphylococcus aureus ${ }^{4}\left(\mathrm{UFC} \mathrm{g}^{-1}\right)$ & $10^{3}$ & $5 \times 10^{2}$ & Ausente & Ausente & Ausente \\
\hline Bactérias aeróbias mesófilas ${ }^{5}\left(\mathrm{UFC} \mathrm{g}^{-1}\right)$ & $10^{6}$ & $10^{6}$ & $2,4 \times 10^{5}$ & Ausente & Ausente \\
\hline Bolores e leveduras ${ }^{6}\left(\mathrm{UFC} \mathrm{g}^{-1}\right)$ & $10^{6}$ & $10^{6}$ & Ausente & Ausente & Ausente \\
\hline
\end{tabular}

${ }^{1} \mathrm{CMSP}=$ carne mecanicamente separada de pirarucu; ${ }^{2} \mathrm{HPPEM}=$ hidrolisado proteico de pirarucu obtido com enzima microbiana; ${ }^{3} \mathrm{HPPEC}=$ hidrolisado proteico de pirarucu obtido com enzima comercial; ${ }^{4}$ Padrões estabelecidos pela RDC no 12 de 02/01/2001 da Agência Nacional de Vigilância Sanitária (Brasil 2001); ${ }^{5}$ Padrões estabelecidos pela International Commission on Microbiological Specifications for Foods (ICMS 1983); ${ }^{6}$ Padrões utilizados por Manske et al. (2011). NMP = número mais provável; UFC = unidades formadoras de colônia. 
Tabela 3. Composição de aminoácidos da CMSP e dos hidrolisados proteicos de pirarucu (Manaus, AM, 2013).

\begin{tabular}{|c|c|c|c|c|c|c|c|}
\hline \multirow{2}{*}{$\begin{array}{c}\text { Aminoácido } \\
\mathrm{g} 100 \mathrm{~g}^{-1} \text { proteína }\end{array}$} & \multicolumn{2}{|c|}{$\mathrm{CMSP}^{1}$} & \multicolumn{2}{|c|}{ HPPEC $^{2}$} & \multicolumn{2}{|c|}{ HPPEM $^{3}$} & \multirow{2}{*}{$\begin{array}{c}\text { Necessidades } \\
\text { de } \mathrm{AAE}^{4}\end{array}$} \\
\hline & AA & EAE & AA & EAE & AA & EAE & \\
\hline \multicolumn{8}{|l|}{ Essencial } \\
\hline Isoleucina & $5,11^{\mathrm{A}} \pm 0,11$ & $1,70^{\mathrm{A}} \pm 0,04$ & $3,87^{\mathrm{B}} \pm 0,16$ & $1,29^{\mathrm{B}} \pm 0,05$ & $3,27^{\mathrm{B}} \pm 0,48$ & $1,2^{\mathrm{B}} \pm 0,05$ & 3,0 \\
\hline Leucina & $8,80^{\mathrm{A}} \pm 0,04$ & $1,49^{\mathrm{A}} \pm 0,01$ & $7,00^{\mathrm{B}} \pm 0,24$ & $1,19^{\mathrm{C}} \pm 0,04$ & $6,43^{\mathrm{C}} \pm 0,12$ & $1,09^{\mathrm{C}} \pm 0,02$ & 5,9 \\
\hline Lisina & $7,64^{\mathrm{A}} \pm 0,24$ & $1,70^{\mathrm{A}} \pm 0,05$ & $6,89^{\mathrm{C}} \pm 0,10$ & $1,53^{\mathrm{B}} \pm 0,02$ & $7,19^{\mathrm{B}} \pm 0,02$ & $1,60^{\mathrm{B}} \pm 0,00$ & 4,5 \\
\hline Metionina + cisteína & $5,12^{\mathrm{A}} \pm 0,12$ & $2,33^{\mathrm{A}} \pm 0,05$ & $3,86^{\mathrm{B}} \pm 0,01$ & $1,90^{\mathrm{B}} \pm 0,25$ & $2,98^{\mathrm{C}} \pm 0,03$ & $1,36^{\mathrm{C}} \pm 0,02$ & 2,2 \\
\hline Fenilalanina + tirosina & $8,30^{\mathrm{A}} \pm 0,19$ & $2,18^{\mathrm{A}} \pm 0,05$ & $6,31^{\mathrm{B}} \pm 0,21$ & $1,66^{\mathrm{B}} \pm 0,06$ & $4,03^{\mathrm{C}} \pm 0,16$ & $1,06^{\mathrm{C}} \pm 0,04$ & 3,8 \\
\hline Treonina & $5,10^{\mathrm{A}} \pm 0,12$ & $2,22^{\mathrm{A}} \pm 0,05$ & $4,12^{\mathrm{B}} \pm 0,15$ & $1,79^{\mathrm{B}} \pm 0,07$ & $3,26^{\mathrm{C}} \pm 0,05$ & $1,42^{\mathrm{C}} \pm 0,02$ & 2,3 \\
\hline Valina & $5,30^{\mathrm{A}} \pm 0,11$ & $1,36^{\mathrm{A}} \pm 0,03$ & $4,26^{\mathrm{B}} \pm 0,12$ & $1,09^{\mathrm{B}} \pm 0,03$ & $3,18^{\mathrm{C}} \pm 0,09$ & $0,82^{\mathrm{C}} \pm 0,02$ & 3,9 \\
\hline Histidina & $2,47^{\mathrm{A}} \pm 0,01$ & $1,65^{\mathrm{A}} \pm 0,01$ & $1,98^{\mathrm{B}} \pm 0,01$ & $1,32^{\mathrm{B}} \pm 0,00$ & $1,46^{\mathrm{C}} \pm 0,01$ & $0,97^{\mathrm{C}} \pm 0,01$ & 1,5 \\
\hline Triptofano & $0,52^{\mathrm{A}} \pm 0,03$ & $0,87^{\mathrm{B}} \pm 0,05$ & $0,94^{\mathrm{A}} \pm 0,02$ & $1,57^{\mathrm{C}} \pm 0,03$ & $0,36^{\mathrm{C}} \pm 0,00$ & $0,60^{\mathrm{C}} \pm 0,00$ & 0,6 \\
\hline \multicolumn{8}{|l|}{ Não essencial } \\
\hline Aspartato & $10,68^{\mathrm{A}} \pm 0,28$ & & $9,18^{\mathrm{B}} \pm 0,36$ & & $8,19^{C} \pm 0,32$ & & \\
\hline Glutamato & $17,33^{\mathrm{A}} \pm 0,24$ & & $14,60^{\mathrm{B}} \pm 0,39$ & & $15,6^{\mathrm{C}} \pm 0,52$ & & \\
\hline Serina & $4,82^{\mathrm{A}} \pm 0,03$ & & $3,98^{\mathrm{B}} \pm 0,09$ & & $3,40^{\mathrm{C}} \pm 0,62$ & & \\
\hline Glicina & $6,19^{A} \pm 0,01$ & & $4,70^{\mathrm{C}} \pm 0,12$ & & $5,11^{\mathrm{B}} \pm 0,20$ & & \\
\hline Arginina & $7,46^{\mathrm{A}} \pm 0,17$ & & $5,73^{\mathrm{B}} \pm 0,03$ & & $5,39^{\mathrm{C}} \pm 0,06$ & & \\
\hline Alanina & $7,16^{\mathrm{A}} \pm 0,07$ & & $5,85^{\mathrm{C}} \pm 0,12$ & & $6,31^{\mathrm{B}} \pm 0,10$ & & \\
\hline Prolina & $4,61^{\mathrm{A}} \pm 0,00$ & & $3,61^{\mathrm{B}} \pm 0,07$ & & $3,08^{\mathrm{C}} \pm 0,09$ & & \\
\hline
\end{tabular}

Cada valor representa a média da triplicata com desvio-padrão. Valores médios de aminoácidos (AA) seguidos por diferentes letras maiúsculas, na mesma linha, indicam diferença significativa pelo teste Tukey $(\mathrm{p}<0,05)$. Valores médios de escore de aminoácidos essenciais (EAE) seguidos por diferentes letras minúsculas, na mesma linha, indicam diferença significativa pelo teste Tukey $(\mathrm{p}<0,05) .{ }^{1} \mathrm{CMSP}=$ carne mecanicamente separada de pirarucu; ${ }^{2} \mathrm{HPPEC}=\mathrm{hidrolisado}$ proteico de pirarucu obtido com enzima comercial; ${ }^{3} \mathrm{HPPEM}=$ hidrolisado proteico de pirarucu obtido com enzima microbiana; ${ }^{4}$ Necessidades de aminoácidos essenciais (AAE) para adultos (WHO 2007).

da lisina. A avaliação dos aminoácidos limitantes dos hidrolisados baseada no EAE indicou que o HPPEC supera as exigências de aminoácidos essenciais da proteína padrão, sendo considerado, portanto, proteína de alto valor nutricional. Todavia, no HPPEM, valina, histidina e triptofano foram os aminoácidos limitantes, sendo o triptofano o aminoácido mais limitante $(\mathrm{EAE}=0,6 \%$ ou $60 \%)$. Resultados similares foram obtidos por Amiza et al. (2013).

Nesta pesquisa, o conteúdo de aminoácidos dos produtos finais está de acordo com os valores relatados por Chalamaiah et al. (2012) e o perfil de aminoácidos de HPPEC foi superior ao do padrão sugerido para seres humanos adultos pela WHO (2007). Portanto, esse produto demonstrou propriedade de suprir o organismo humano adulto com níveis adequados de aminoácidos essenciais. Em função da presença de aminoácidos limitantes, o hidrolisado HPPEM deve ser utilizado como suplemento proteico, isto é, associado a proteína com elevado teor de triptofano, histidina e valina, para que ocorra adequada complementação aminoacídica.

Os hidrolisados proteicos apresentaram percentual de digestibilidade significativamente superior, em relação à matéria-prima, com 89,32 \% \pm
0,76, para HPPEC, e 92,41\% \pm 0,94, para HPPEM. Em contrapartida, a CMSP apresentou digestibilidade de $62,84 \% \pm 0,54$. O processo utilizado melhorou a digestibilidade da proteína, assim como relatado por Foh et al. (2011), para o hidrolisado proteico de tilápia. Isso ocorre porque, devido à hidrólise enzimática, as proteínas são quebradas em peptídeos menores e aminoácidos livres, o que aumenta a solubilidade e, consequentemente, a digestibilidade das proteínas.

\section{CONCLUSÕES}

1. O hidrolisado proteico de pirarucu obtido com a pancreatina contém teor proteico elevado e perfil de aminoácidos essenciais superior ao hidrolisado proveniente da ação das proteases de A. flavo-furcatis.

2. Apesar das diferenças entre os produtos gerados, ambos apresentam digestibilidade superior à matéria-prima e qualidade microbiológica adequada para consumo.

3. Os dois hidrolisados podem ser utilizados na alimentação humana, contudo, o HPPEC como fonte proteica e o HPPEM como suplemento nutricional associado a outras fontes proteicas. 


\section{REFERÊNCIAS}

AGRAWAL, D. et al. Production of alkaline protease by Penicillium sp. under SSF conditions and its application to soy protein hydrolysis. Process Biochemistry, Indore, v. 39, n. 8, p. 977-981, 2004.

AKESON, W. R.; STAHMAN, M. H. A pepsin-pancreatin digest index of protein quality. Journal of Nutrition, Madison, v. 83, n. 3, p. 857-861, 1964.

AMIZA, M. A.; OW, Y. W.; FAAZAZ, A. L. Physicochemical properties of silver catfish (Pangasius sp.) frame hydrolysate. International Food Research Journal, Rio de Janeiro, v. 20, n. 3, p. 1255-1262, 2013.

ANITHA, T. S.; PAlANIVELU, P. Purification and characterization of an extracellular keratinolytic protease from a new isolate of Aspergillus parasiticus. Protein Expression and Purification, Madurai, v. 88, n. 1, p. 214220, 2013.

ARANTES, C. C.; GARCEZ, D. S.; CASTELlO, L. Densidades de pirarucu (Arapaima gigas, Teleostei, Osteoglossidae) nas reservas de desenvolvimento sustentável Mamirauá e Amanã, Amazonas, Brasil. Uakari, Tefé, v. 2, n. 1, p. 37-43, 2006.

ASSOCIATION OF OFFICIAL ANALYTICAL CHEMISTS (AOAC). Official methods of analysis. 18. ed. Washington, DC: AOAC, 2000.

BRASIL. Instrução Normativa $n^{\circ} 62$ de 26 de agosto de 2003. Oficializa os métodos analíticos oficiais para análises microbiológicas para controle de produtos de origem animal e água. Diário Oficial da União, Brasília, DF, 18 set. 2003. Seção 1, p. 14. Disponível em: <http://extranet. agricultura.gov.br/sislegisconsulta/consultarLegislacao. do?operacaovisualizar\&id=2851 $>$. Acesso em: 08 fev. 2014.

BRASIL. Ministério da Saúde. Agência Nacional de Vigilância Sanitária. Resolução RDC n ${ }^{\circ} 12$ de 02 de janeiro de 2001. Regulamento técnico sobre os padrões microbiológicos para alimentos. Diário Oficial da República Federativa do Brasil, Brasília, DF, 10 jan. 2001. Seção 1, p. 45-53. Disponível em: <http://www.anvisa.gov. br/legis/resol/12_01rdc.htm>. Acesso em: 08 fev. 2014.

CASTELLO, L. et al. Lessons from integrating fishers of Arapaima in small-scale fisheries management at the Mamirauá reserve, Amazon. Environmental Management, Nova York, v. 43, n. 2, p. 197-209, 2009.

CHALAMAIAH, M. et al. Fish protein hydrolysates: proximate composition, amino acid composition, antioxidant activities and applications: a review. Food Chemistry, Hyderabad, v. 135, n. 4, p. 3020-3038, 2012.

CHOULHARY, V. Production, isolation and characterization of alkaline protease from Aspergillus versicolor $\mathrm{PF} / \mathrm{F} / 107$. Journal of Academia and Industrial Research, Sagar, v. 1, n. 5, p. 272-277, 2012.

FOH, M. B. K. et al. Chemical and physicochemical properties of tilapia (Oreochromis niliticus) fish protein hidrolysate and concentrate. International Journal of Biological Chemistry, Jiangsu, v. 5, n. 1, p. 21-36, 2011.

FONSECA, T. R. B.; BARRONCAS, J. F.; TEIXEIRA, M. F. S. Produção em matriz sólida e caracterização parcial das proteases de cogumelo comestível da Floresta Amazônica. Revista Brasileira de Tecnologia Agroindustrial, Manaus, v. 8, n. 1, p. 1227-1236, 2014.

FOOD AND AGRICULTURE ORGANIZATION (FAO).

Peces natives de agua dulce de América del Sur de interés para la acuicultura: una sínteses del estado de desarrollo tecnológico de su cultivo. Lima: FAO, 2010.

FREITAS-JÚNIOR, A. V. C. et al. Giant Amazonian fish pirarucu (Arapaima gigas): its viscera as a source of thermostable trypsin. Food Chemistry, Recife, v. 133, n. 4, p. 1596-1602, 2012.

GALLA, N. R. et al. Functional properties and in vitro antioxidant activity of roe protein hydrolysates of Channa striatus and Labeo rohita. Food Chemistry, Hyderabad, v. 135, n. 3, p. 1479-1484, 2012.

HOYLE, N.; MERRIT, J. H. Quality of fish protein hydrolysate from herring. Journal of Food Science, Chicago, v. 59, n. 1, p. 4769-4774, 1995.

IN TERNATIONAL COMMISSION ON MICROBIOLOGICAL SPECIFICATIONS FOR FOODS (ICMS). Microrganismos de los alimentos: técnicas de análisis microbiológicos. Zaragoza: Acribia, 1983.

KIRSCH, L. S. et al. Partition of proteases from Lentinus citrinus DPUA 1535 by the peg/phosphate aqueous two-phase system. Química Nova, Manaus, v. 35, n. 10, p. 1912-1915, 2012.

KLOMPONG, V. et al. Antioxidant activity and functional properties of protein hydrolysate of yellow stripe trevally (Selaroides leptolepis) as influenced by the degree of hydrolysis and enzyme type. Food Chemistry, Hat Yai, v. 102, n. 4, p. 120-131, 2007.

KRANTHI, V. S.; MURALIDHAR, R. D.; JAGANMOHAN, P. Production of protease by Aspergillus flavus through solid state fermentation using different oil seed cakes. International Journal of Microbiological Research, Nandyal, v. 3, n. 1, p. 12-15, 2012.

LI, Z. Y.; YOURAVONG, W.; KITTIKUN, A. H. Protein hydrolysis by protease isolated from tuna spleen by membrane filtration: a comparative study with commercial proteases. Food Science and Technology, Hat Yai, v. 43, n. 1, p. 166-172, 2010. 
MANSKE, C. et al. Composição centesimal, microbiológica e sensorial do jundiá (Rhamdia quelen) submetido ao processo de defumação. Semina: Ciências Agrárias, Londrina, v. 32, n. 1, p. 181-190, 2011.

MUELLER, O.; GREEN, A. Arapaima gigas - market study: current status of arapaima global trade and perspectives on the Swiss, French and UK markets. Cocha El Dorado: UNCTAD, 2005.

NEVES, R. A. M.; DE MIRA, N. V. M.; MARQUEZ, U. M. L. Caracterização de hidrolisados enzimáticos de pescado. Ciência e Tecnologia de Alimentos, Campinas, v. 24, n. 1, p. 101-108, 2004.

NGUYEN, H. T. M. et al. Enzymatic hydrolysis of yellow fin tuna (Thunnus albacares) by-products using protamex protease. Food Technology Biotechnology, Nantes, v. 49, n. 1, p. 48-55, 2011.

NILSANG, S. et al. Optimization of enzymatic hydrolysis of fish soluble concentrate by commercial proteases. Journal of Food Engineering, Bangkok, v. 70, n. 4, p. 571$578,2005$.

OLIVEIRA, M. S. R.; FRANZEN, F. L.; TERRA, N. N. Utilização da carne mecanicamente separada de frango para a produção de hidrolisados proteicos a partir de diferentes enzimas proteolíticas. Semina: Ciências Agrárias, Londrina, v. 35, n. 1, p. 291-302, 2014.

PACHECO, M. T. B. et al. Propriedades funcionais de hidrolisados proteicos obtidos a partir de concentrados proteicos de soro de leite. Ciência e Tecnologia de Alimentos, Campinas, v. 25, n. 2, p. 333-338, 2005.

RODARTE, M. P. et al. Proteolytic activities of bacteria, yests and filamentous fungi isolated from coffee fruit (Coffea arabica L.). Acta Scientiarum Agronomy, Maringá, v. 33, n. 3, p. 457-464, 2011.

SANDHYA, C. et al. Comparative evaluation of neutral protease production by Aspergillus oryzae in submerged and solid state fermentation. Process Biochemistry, Budapeste, v. 40, n. 8, p. 2689-2694, 2005.

SOUZA, F. C. A. et al. Efeito do congelamento na composição química e perfil de aminoácidos da carne mecanicamente separada de peixes amazônicos. Revista Pan-Amazônica de Saúde, Manaus, v. 4, n. 1, p. 57-61, 2013.

SPIES, J. R. Determination of tryptophan in proteins. Analytical Chemistry, Washington, DC, v. 39, n. 12, p. 1412-1416, 1967.

TEIXEIRA, M. F. S. et al. Enzimas de linhagens de Aspergillus flavo furcatis: novas fontes proteolíticas da biodiversidade amazônica. In: MARCON, J. L. et al. (Eds.). Biodiversidade amazônica: caracterização, ecologia e conservação. Manaus: Edua, 2012. p. 45-54.

UPADHYAY, M. K. et al. Optimization and characterization of an extracellular proteases from Aspergillus flavus "MTCC 277". African Journal of Agricultural Research, Jaipur, v. 5, n. 14, p. 1845-1850, 2010.

VEIT, J. C. et al. Desenvolvimento e caracterização centesimal e microbiológica de hidrolisados proteicos de tilápia do Nilo (Oreochromis niloticus). Revista Brasileira de Pesquisa em Alimentos, Campo Mourão, v. 4, n. 1, p. 27-34, 2013.

WHITE, J. A.; HART, R. J.; KRY, J. C. An evaluation of the waters pico-tag system for the amino acid analysis of food materials. Journal of Automatic Chemistry, Leatherhead, v. 8 , n. 4, p. $170-177,1986$.

WORLD HEALTH ORGANIZATION (WHO). Protein and amino acid requirements in human nutrition: report of a joint $\mathrm{WHO} / \mathrm{FAO} / \mathrm{UNU}$ expert consultation. Geneva: WHO, 2007. (Technical report, 935).

ZAVAREZE, E. R. et al. Funcionalidade de hidrolisados proteicos de cabrinha (Prionotus punctatus) obtidos a partir de diferentes proteases microbianas. Química Nova, Rio Grande, v. 32, n. 7, p. 1739-1743, 2009. 